\title{
Play as a Player in Design. Rethinking a 'Curious Practice' for Co-designing Public Space
}

\author{
Laura Winge, Anne Margrethe Wagner, Bettina Lamm \\ University of Copenhagen, Denmark \\ lawi@ign.ku.dk | amw@ign.ku.dk | bela@ign.ku.dk
}

\begin{abstract}
'Move the Neighbourhood' is a research project experimenting with co-designing playable installations for a public green space in Copenhagen through a design-based collaboration between children and design-researchers.

We employed a co-design process to investigate whether deconstructing the rules for both play and design could trigger new ways of conceiving and realizing playable spaces. The aim was to test a participatory process in order to identify what might be meaningful in relation to both play and designing for play, along a spectrum ranging from rules to collaborative improvisation.

In this article, we investigate how play can create agency, spark imagination and open up practices in both artistic and academic processes. Drawing on Barad's concept of 'intraaction', we suggest design/play as a dynamic engine for exploring collaborative design practices as a dialogue between art, play and co-design. In our co-design approach, we seek to unfold what Haraway calls 'response-ability' to a 'curious practice', exploring the unanticipated in the collaboration as a potential for transforming space.

The metaphor of a 'jelly cake' from play-research helps us to activate the messiness of play and frames our methodological approach to collaborative design. We see play as a serious co-player that evokes collective worlds through productive fields of action that enable actors to engage in the co-design of playable public space.
\end{abstract}

Keywords: co-design, play, participation, children, urban design, public space, curious practice, polite visiting

To cite this article:

Winge, L., Wagner, A. M., Lamm B. (2020). Play as a Player in Design. Rethinking a 'Curious Practice' for Co-designing Public Space, The Journal of Public Space, 5(4), 25-44, DOI I0.3289I/jps.v5i4.1312

This article has been double blind peer reviewed and accepted for publication in The Journal of Public Space. (c) (1) This work is licensed under a Creative Commons Attribution - Non Commercial 4.0 International License https://creativecommons.org/licenses/by-nc/4.0/ 


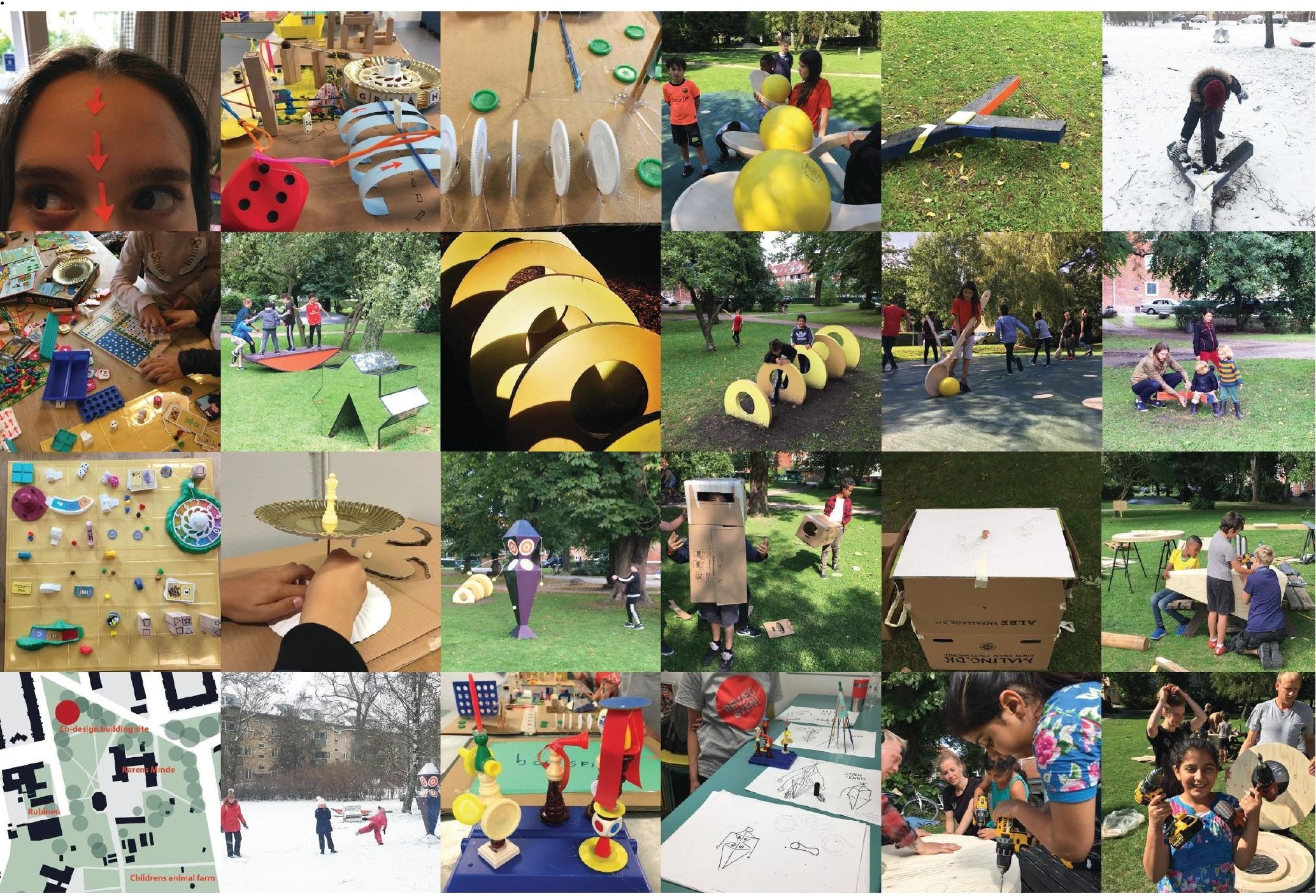

Figure I. Visual abstract: design matters in an entangled materiality discourse. According to Solnit, artistic work can 'open doors and invite in prophesies, the unknown, the unfamiliar' (Rebecca Solnit 2006, A Field Guide to Getting Lost, p.5). Photos: Winge. Except photo of circles: A. Millar.

\section{Introduction}

In the research project 'Move the Neighborhood with Children', we worked with children to co-design visions for a playable space, and then materialized those visions in the design and construction of playable installations for a public green space in Copenhagen.

Over a three-week period in August 2017, we collaborated with 20 children (aged II15) from Rubinen youth club in the Sydhavnen neighbourhood. The aim was to revitalize the green lawn in a public park next to the youth club with playable installations developed through a series of co-design workshops. Five installations emerged from the collaborative design process that played out between children, design researchers and a team of carpenters. The children participated voluntarily, deciding 
from day to day whether they wanted to join. The participants came from the same group of children, and numbered on average 15 per day.

The co-design workshops explored future scenarios for the community site. The outcome was five wooden figures set amongst the trees. Combined, they created a playable social space that included a rocking-boat, an oversized slingshot, a mirror stargate, a tetherball totem and a line of disc-shaped goals (Figure 2). These became visual destinations that offer different possibilities for playful actions, inventing games or hanging out.

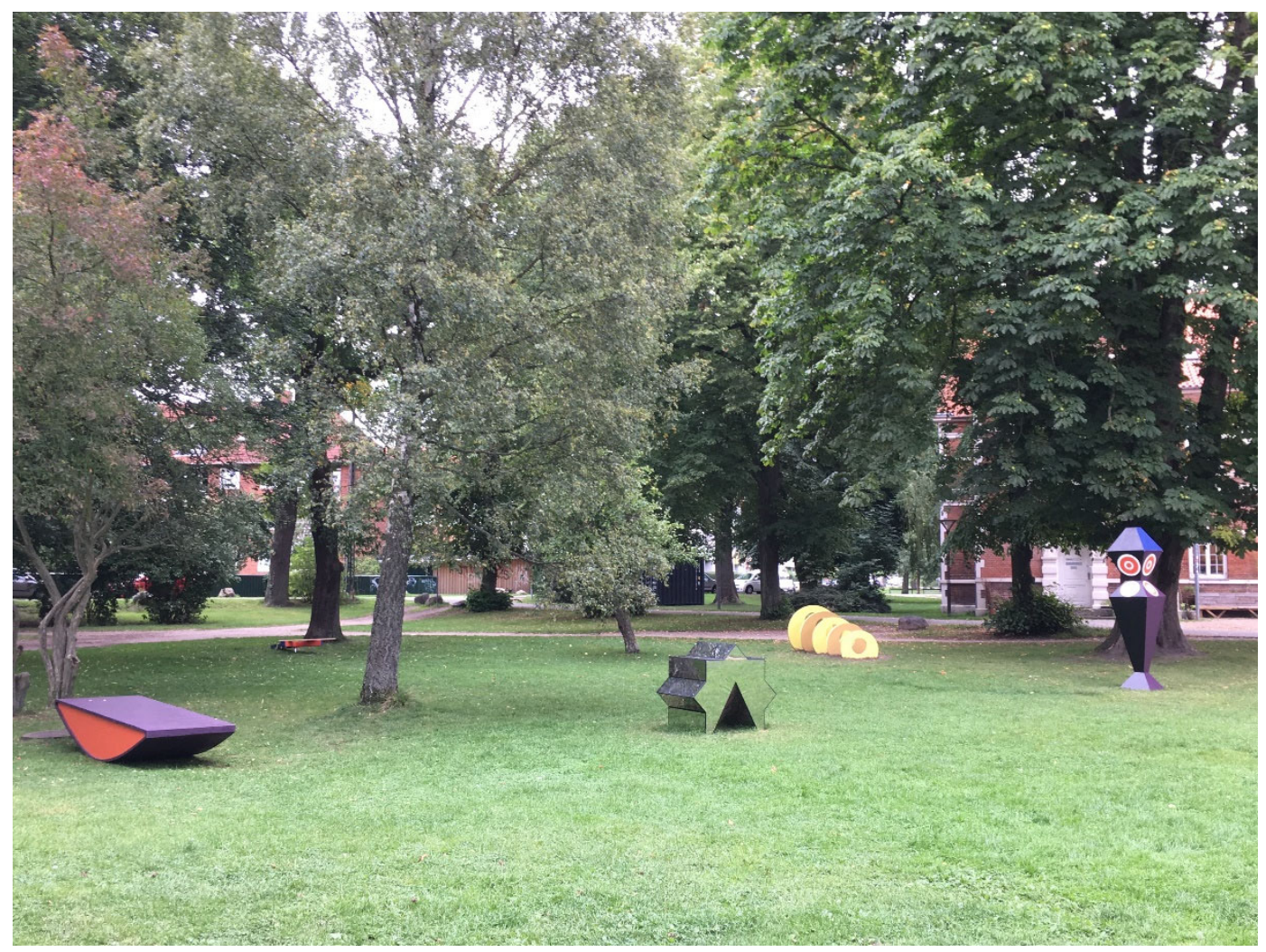

Figure 2. The playscape. Photo: Winge.

The playscape worked on several levels: as a sculpture park, a set of activities, and a site that encourages children and others to invent new rules for engaging with it over time. The figures are open for interpretation: The mirror star-gate reflects the landscape, like a tiny magic passageway that merges into its environment. Small children can crawl through it, or a ball can be fired through it at great speed from the slingshot. Children can climb the disc-shaped goals and try to get a ball through all of them in one shot. The tetherball totem invites users to hit the targets on the front with the tennis balls attached by elastic bands. On the rocking-boat, you can 'sail' the green lawn, across a sea of grass.

\section{Our co-design approach}

Participatory design can set the scene for alternative futures. Through collaborations with citizens, it can support democratic change and materialize visions in public, thereby 
merging the production sphere with the public sphere (Ehn et al. 20I4). Within participatory design, co-design is a particular approach, in which designers design with users, not for them (Sanders \& Stappers 2008).

In co-design, what is being designed is not only the artifact, but also the process that enables participants to engage in designing the artifact (Robertson \& Simonson 2013). When children take part in participatory design practices, their participation is significantly influenced by the physical spatial context, but also by the specific child-adult relationship in which the design takes place (Vaneycken 2020). As designers and researchers, we fulfil several roles in the collaborative process: we set direction by structuring and curating the workshops, we facilitate the ongoing interaction and decision-making, engage in design proposals and creations, and analyse and unpack what took place in the process.

As co-designers, we are aware of our ambiguous position when we invite children to explore the language of design through selectively curated workshops based on specific aims. We aim to address this position in a transparent manner and use it proactively in both practice and research.

In our approach, we see co-design as a way to engage and combine 'telling, making, and enacting' through various methods and collaborations, thereby 'forming a temporary community in which the new can be envisioned' (Brandt et al. 2012, p. 145). Participatory designers/researchers use various modalities for tracking and unpacking what happens in the design process, such as notes, photographs, drawings and artifacts. This is how we build stories and design, but they are also our empiric material and basis for research. This type of knowledge production is developed through active collaborative design processes (co-design) situated in specific design projects (Robertson \& Simonson 20I3).

Our material-based workshops play a central role. They constitute a 'more-than-human world' (Hackett \& Somerville 2017) in which ideas, schedules, models, glue pistols and cardboard boxes interact. Maintaining an awareness of material-discursive relations (Barad 2007; Hackett \& Somerville 2017) focuses our attention on the relational and transformational situations that take place in the process. To look at these agencies is to focus on 'the codependency between humans and the more-than-human world, and understandings of the vibrational movement of humans and non-humans are central to this' (Hackett \& Somerville 2017, p. 379-380). Hackett and Somerville (2017) propose these movements as a 'communicative practice' that occurs as a complex entanglement of relations within more-than-human worlds. They assert that context and materials 'ask questions' of the children: 'their [the children] gestures and movements in response to those questions can be understood as a worldforming communicative practice where words, story, imagination, movement and gesture are inseparable from the simultaneous actions [of context and material]' (Hackett \& Somerville 2017). In our case, these responses could also take the form of design, e.g. models and drawings or play. This research approach draws on a material-discursive perspective, and specifically on intra-action, a theoretical concept suggesting that not only humans, but objects, and other materialities have agency, and are all capable of shaping our world (Barad 2003). The intra-action theory is based on mutually transformative interactions between human and non-human actors, and between discourse and materiality (Lykke 2008, p.23I). Barad describes intra-action as a 'mutual constitution of entangled agencies' (Barad 2007, p. 139), which means that discourses, matter, material, nature, subjects and 
objects have agency - the ability to act - that emerges from within a relationship. Through intra-actions, new entangled agencies are constituted: 'Individuals materialize through intra-actions and the ability to act emerges from within the relationship not outside of it' (Stacey Kerr, S. et al. 2017). This way of thinking is of particular interest for design research, because it frames how our transformative ability emerges through intra-actions.

\section{Co-design as a curious practice}

Curiosity always leads its practitioners a bit too far off the path, and that way lies stories. (Haraway 2016, p. I28)

According to the STS scholar Donna Haraway, 'a curious practice' requires that we as (design-)researchers train our whole being - not just our imagination - to explore: 'calling as if the world mattered, calling out, going too far, going visiting' and 'to cultivate the wild virtue of curiosity, to retune one's ability to sense and respond - and to do all this politely!' (Haraway 20 I5, p.5). She states that 'training the mind and imagination to go visiting [...]' constitutes meeting the unexpected and establishing conversations; 'to pose and respond to interesting questions, to propose together something unanticipated, to take up the unasked-for obligations of having met'. She calls this 'cultivating response-ability' (Haraway 2016, p. I30). In co-design, 'response-ability' consists of being able to respond to each other via our senses and curiosity, thereby igniting a collective imagination through design actions.

We paid attention to cultivating response-ability in our engagement with the children's ideas, inputs, and inner worlds. Here, children and researchers do something, and do it together. 'They become-with each other', as Haraway describes the inevitable entanglement of the observing researcher with the liveliness of the ones being observed (Haraway 2016 p. 128). In other words, when codesigning together we join a collective community of designing, in which the co-design approach affects both the relationships within this community, and the methods involved in creating new realities. The design process was a messy pool of playing, creating artefacts, disruption and detours, and resembled what Haraway terms a 'subject-and-object-making dance', in which subjects and objects are in intra-action (Haraway 20I5, p.6). In this process, the 'subject-and-object-making dance' constitutes the curious practice. It reflects an inductive approach to co-design practice, based on 'reflection-in-action' (Schön 1983). For us, as both researchers and designers, a 'curious practice' meant caring about and exploring how knowledge and transformation was produced in the 'subject-and-objectmaking dance'.

\section{Play as the context and driver of the design-process}

In the project, we decided to use the concept of play as a 'player' to challenge both the format and content of the collaborative process. According to the sociologist Caillois, play can be understood as situated between rules (ludus) and self-directed 'free play' (paidia), in which players define their own rules (Caillois 196I, in Vaneycken, Hamers et al. 2017). We designed the co-design process as an interaction between ludus and paidia. We tested whether the use of play to deconstruct rules could trigger new ways 
of conceiving and realizing playable spaces, and develop open-ended designs that encouraged free play.

We curated the workshop-design to spark reflection on the relation between game rules and free play. Using a design vocabulary based on games and gameplay, we encouraged children to design artifacts and invent rules for play. We introduced the ball as a prop to illustrate and activate aspects related to ludus and paidia. These concepts became instrumental in curating the design process towards outcomes that pushed the boundaries for how we conceive spaces for play and a framework for opening up design activities.

Play can be a driver for escaping habits and cultivating openness in a collaborative design practice and in the exchange between children and design. Neither research, play nor design processes are linear. As designers and researchers, we sought to curate a codesign process that was structured, and yet open to playful thinking, spontaneity and irregularity. We thereby employed an inductive approach intended to open 'doors and invite in prophesies, the unknown, the unfamiliar' (Solnit 2006, p.5).

In the design process, we framed dialogue through playful making and testing. Play is not a structured methodological approach, but can appear messy and chaotic. Law (2006) advocates for research methodologies that embrace mess. This is an understanding of research that unfolds and engages with a messy world: 'We need to understand that our methods are always more or less unruly assemblages' (Law 2006, p. 14). 'In practice research needs to be messy and heterogeneous. [...] because that is the way the largest part of the world is - messy, unknowable in a regular and routinised way. [...] Clarity doesn't help. Disciplined lack of clarity, this may be what we need' (Law 2006, p. 2).

\section{The 'jelly cake' - Play as an opener of design}

Play and design scholar Helle Skovbjerg defines play as an activity in which participants join and create a new 'universe of meaning' through actions. Play can open up new meanings and practices that might seem chaotic, but which reframe the participants' understanding of what constitutes a meaningful practice (Skovbjerg 2018). Here, parallels to co-design can be drawn. Vaneycken (in Hamers et al. 2017) connects the participatory elements in children's paidia with participatory engagement in co-design. Here, designing with children is a creative (empowering) process that enables children to reform or break rules, and to de-control predefined roles (Vaneycken in Hamers et al. 2017). While some participants consider this a messy experience, for others it is a developmental process. We see play as a potential opener of new practices, creating a 'new universe of meaning' within the collaborative practice.

Skovbjerg is concerned with the linguistic tendency to flatten the experience of play (Skovbjerg 2019). In her search for a poetic language to convey the sense of the phenomenon, she uses the 'jelly cake' as a metaphor for the ontology of play:

Imagine holding your hands around a jelly cake, not squeezing it too hard but still holding it, showing it to others, maybe eating it with good friends. That jelly cake is the type of language required here. (Skovbjerg 2018, p.6)

When writing about play, we must track our experiences (Skovbjerg 2019). The jelly cake is a metaphor for the fun and vibrant shared experience of play when we participate as active co-players. However, this is a 'slippery phenomenon', dealing with 
something undefined (Law 2006), and therefore the metaphor also conveys the messy and playful experience of co-design.

When designing for play, we must question to what extent we are allowing a degree of uncertainty or supporting open-endedness (Skovbjerg 2018, p.19). Play can deconstruct the rules, and be both a disruptive and productive driver of design. The 'jelly-cake-ness' keeps attention on the vibrancy and experiential space that we explore through the play approach.

\section{Design/play}

In this section, we unfold our conceptual framework. Design/play draws on the described theories from fields of research around new materialism, play and collaborative design. We frame design/play as intra-action (Barad, Hackett \& Somerville), based on an understanding of co-design as a curious practice (Haraway), and employing play as an opener of design (Caillois, Skovgaard, Vaneycken). Design/play applies a playful approach to both materials and dialogues within co-design. When codesigning, play and design 'matters' are entangled with materiality and the local spatial context.

We use design/play as a concept to understand the becoming of the playscape, and as a transformative phenomenon that informs and influences the co-design practice. Investigating the co-design process through intra-actions and inviting play as a player opens up possibilities. Entanglements play out through the transforming dynamics and exchanges between design researchers, materiality, children, visions and the becoming of a playable space.

Using design/play as a lens, we can break down boundaries we forgot that we invented (Kerr et. al. 2017), and our ways of seeing the world of play as 'just play', and instead invite play as a co-player into the co-design process with the children. Design/play is a framework with which we see that design and play are entangled as entities that affect, transform and inspire each other. In design/play, playing with matters, materiality and senses affects the design process and the understanding of materiality.

In the following, we will investigate how design/play unfolds in practice. We propose that 'design/play' can enable a 'curious practice' in co-design. It is an entanglement between play and design that generates agency; 'When [...] different things are in relationships with each other our ability to do stuff changes, transforms or emerges' (Barad in Kerr, S. et al. 2017). The ability to act, make and transform, emerges from the design/play relationship. Design/play is the lens via which we explore the case, the agencies in becoming and the resulting design moves and manifestations.

\section{Co-designing through design/play}

In the co-design process with the children from Rubinen youth club, we designed the workshops as open-ended design/play activities. We set up specific aims for each workshop, in order to ask how new design interventions can activate play that promotes engagement with either the body or a ball.

Each co-design workshop led to specific design outcomes - models, actions or installations - that collectively fed into the final playscape design. The design/play iterations reflect a search for future potential interactions in the public space. 
Throughout the process, the children tested designs by playing, and negotiated solutions through drawings, play and discussion: 'Is it fun? Is it a game? How can we engage with it?'

\section{The design process}

The co-design process was organized around five workshops:

A. Making I:I mock-ups of playable installations from cardboard boxes, exploring design ideas and space with the body.

B. Experimenting with rules for play through the improvisational art-game Spoon Ball (Haslund 20I8).

C. Designing and making models from old board games, imagining the lawn as a game board.

D. Three weeks of designing, negotiating and constructing installations on site with carpenters.

E. Celebrating, testing games and playing with the five new installations.

In the following chapter, we will trace how design/play enacted the figures and their becoming through co-designing and making. To understand events through the lens of design/play is to be aware of situations, small or big, in which design/play occurs: children playing 'designers'; the telling of playful stories that unfold the design; developing installations through playful activities; and testing through play.

We explore selected design/play events and trace the intra-actions that led to the design. We present how play intra-acted with space, bodies, and materials in the design process, and how design/play took place. We look at how design/play transformed the participants and the design, through material encounters and power-play in the space. In the following, we will unfold six examples from the co-design process.

\section{Co-design events:}

I. Designing and testing figures for play through world-making

Workshop A, which consisted of making I:I mock-ups, was a play/design investigation into how different figures can activate play. We used cardboard boxes to test and build ideas for installations that could be engaged using either a ball or direct bodily interaction. One group of boys played 'gaming', in which they interpreted the green lawn as a computer game space. Their designs activated characters inside the game with full-sized, portable suits referencing robots and Minecraft. The group wore and engaged with the cardboard mock-ups, becoming living game pieces on site.

In the design/play scenarios, we responded to this interpretation of 'gaming' by mirroring gameplay via tasks ('How fast can we paint this boat?') or motivating incentives ('completion will release a reward' (a cookie)).

Representing pieces in a computer game also became a direct inspiration for workshop C. This event involved designing with 'gaming' by making models from old board games and imagining the lawn as a game board. Children explored design/play through ideas for play installations based on board-game pieces. The children explored how the workshop materials could inspire ideas for obstacle courses, small characters and 'totems' with playful functions.

During the building stage, in workshop $\mathrm{D}$, the playing piece models were upscaled and transformed into body-sized figures on the lawn, including the tetherball totem. This 
installation is a playful hybrid translation of the cardboard characters and one boy's design of a 'totem figure' (Figure 3). In his world, the totem also resembled a character/avatar in a computer game. The completed totem installation was a tall figure with a functionality inspired by tetherball, featuring a target and tennis balls attached to long elastic bands. Play involved pulling the elastic taut and hitting the target with the ball.

The becoming of the tether-ball totem exemplifies the intra-action between children, materials and play, where the design/playing with figures and board game pieces transforms into a tetherball totem. The play with 'gaming' and board-game materials activated the children's world-forming design response through a material design/play dialogue.

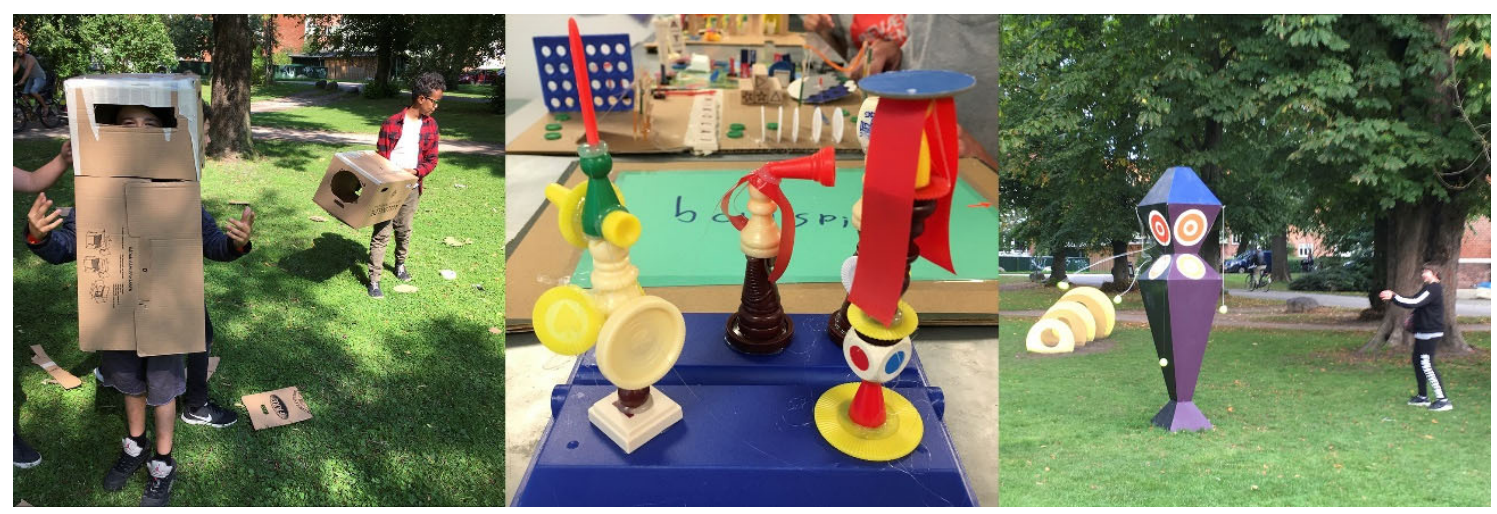

Figure 3. The play and models that drove the tetherball-totem: a boy embodies the material: a character/avatar $>$ a model of a living totem $>$ the tetherball-totem.

The material matters, such as old games, changed and unfolded the design. Photos: Winge.

\section{Exploring the entanglement of scale, ludus and paidia through art and play}

To introduce rules as a driver of play, the scope of workshop B was framed by Molly Haslund's art piece Spoon Ball (Figure 4, Haslund 2018). This socially engaging art performance consists of a playing field and gigantic wooden spoons and balls. In this oversized and open-ended situation, players are encouraged to engage bodily and invent their own rules for Spoon Ball. Spoon Ball set the scene for play through artifacts.

According to Haraway, it matters what stories and objects we use to tell stories; 'it matters what stories make worlds, what worlds make stories' (Haraway 2016, p. 12). Spoon Ball is a 'design-story' about engaging with playable design and understanding play as a phenomenon. We used it as a curatorial hack, to directly experience the relations between design, games (ludus) and play.

We introduced Spoon Ball with a story explaining how ludus influences the meaning of play:

If we don't know the rules of football, it might look strange to an outsider. If aliens looked at football from outer space, they would say: 'What are they doing down there?' (Winge 2017)

The children tested Spoon Ball through paidia. We set up a match with few rules - you 'die' if a 'spooner' throws a ball and hits you. Playing Spoon Ball was an inquiry into ludus and paidia. We tried to catch each other in unruly ways for which we had no name, and ended up getting confused and making rules (ludus) to structure the play. We 
discussed how the design of the rules was essential to the play, and how surprising design (the oversized spoons) appealed to the players' sense of the fantastical.

Spoon Ball showed that rule-making can inspire free play, and demonstrated how ideas can be negotiated through bodily gestures and the design of our physical surroundings. It helped the children understand play as a phenomenon, and established a relationship between ludus and paidia - play and design. The absurdly oversized spoons showed that figuration could stimulate play by itself, and that this 'game', through its tools, both referred to and opposed existing rules.

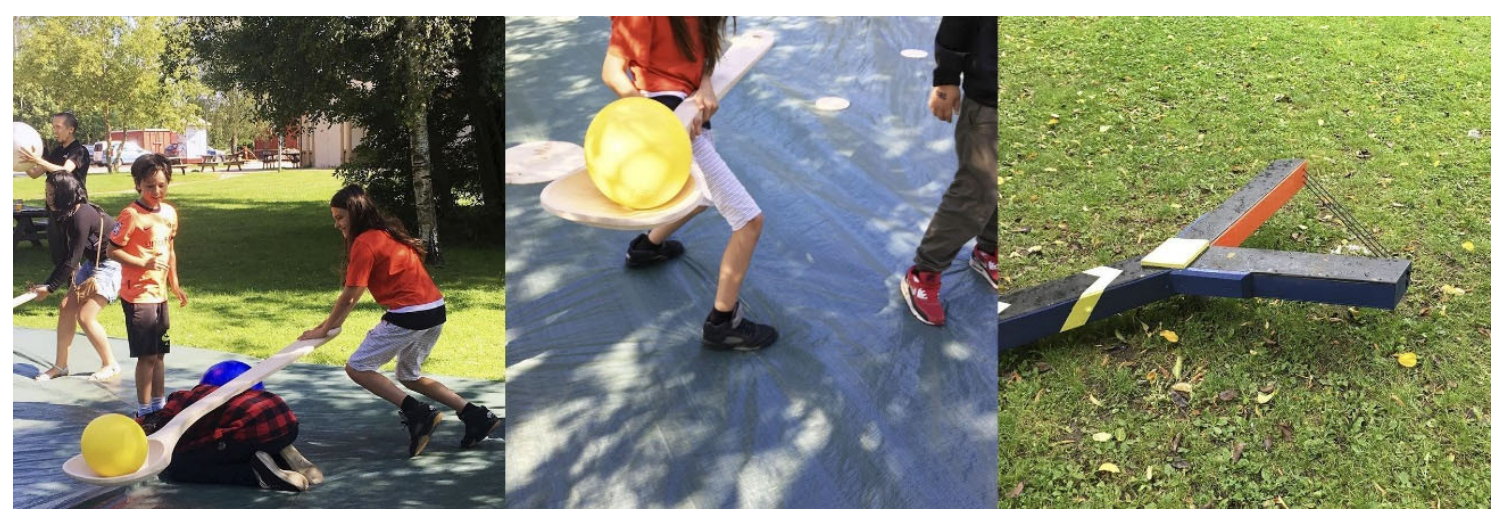

Figure 4. How playing with scale and rules led to playful thoughts in a more-than-human world: Spoon Ball played on-site > an oversized slingshot. 'Let's oversize something,' a boy said during the design process. This led to playful thoughts: 'If you oversize an object, you can interpret the children as being downsized. Does this understanding affect public space if the people are very tiny?' (Winge 2017). Photos: Winge.

Spoon Ball illustrated a more-than-human world (Hackett \& Somerville 2017, p. 379380 ), in which the relationships between humans and non-humans were central to the expansion of play. The design of Spoon Ball and the play with the enactment of rules were inseparable entities in their intra-actions. Later, it inspired the design of the oversized slingshot (Figure 4) that enacted the play with scaling up and down, a game world shooting and aiming at targets. This connection between scale and place played a role in the following workshop, in which the lawn was perceived as a game board.

\section{Old games as matters to think new matters with}

In workshop $\mathrm{C}$, the research team set the table with a big pile of disassembled game boards, play pieces of all sorts, cards, and colourful materials. The aim was to cultivate ideas and test potential installations for the site through building models based on board games. While making small-scale representations of installations, the lawn was conceived as a game board (Figure 5). This continued the theme of design/play via paidia and ludus. The materials lent new associations to the design/play activity - 'it matters what matters we use to think other matters with' (Haraway 2016, p.I2). These game materials inspired the design of new games. Seeing the site as a game board transformed us, the children, the trees and the future installations into upscaled game pieces. In the workshops, we explored how we could design objects that would lead players to intuitively understand 'the rules' for how to activate the designs through play. 


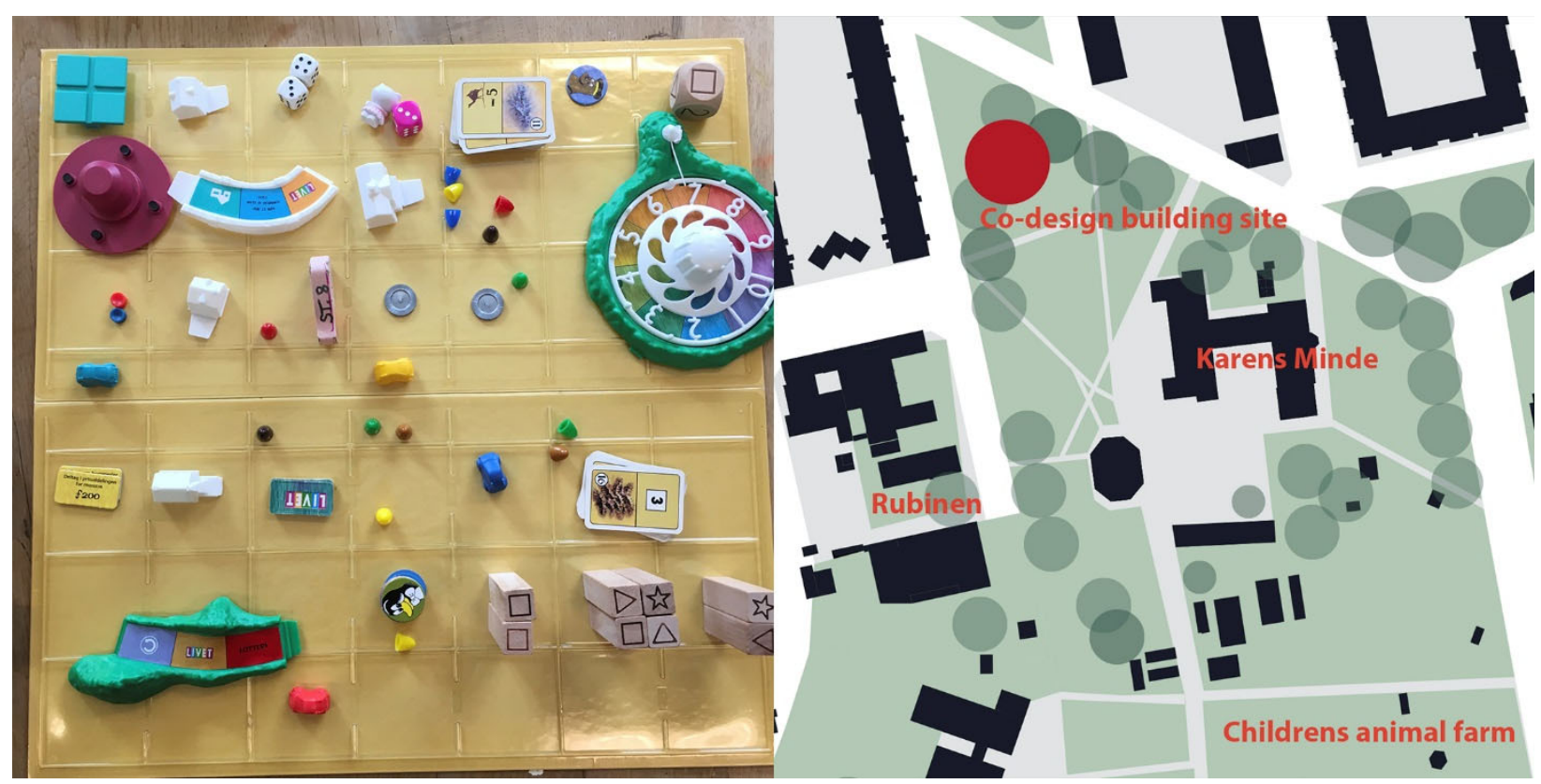

Figure 5. The site from above and a comparison between two representations of the green space: a constructed board game depicting the lawn (left) and a map of the green space. The installations on the lawn were conceived as a board game. Photo: Winge. Map: Carroza.

One boy built an abstract model with five discs set in a row. He presented it as an 'obstacle course' with different levels, while he 'walked' playfully through it with two fingers to test how to 'play' them (Lamm 2017). On the lawn, the model discs were translated into an installation, and we added holes to open them up for play with a ball (Figure 6). Holes became a recurring theme throughout the design process: models with small holes for the bodily performance of a finger, bigger holes for balls, heads, eyes and bodies.

The models acted as miniature obstacle courses, with the pieces representing players on site. Some children discussed achieving different 'levels', as in gaming. Design/play with real space, through both imaginary computer games and the old game boards, took place via designing and playing with the models. The game pieces became personas totems representing the children themselves. This entanglement of games and space allowed the children to understand the scale of the design and how the space would be transformed. The old board games generated a transformation, a designing of new matters. Here, design/play unfolded and changed the old game pieces into new design, with new rules of play.

Although the translation of small models into actual installations was very direct, this jump in scale, and from idea to reality, could be surprising. The boy who modelled the circular discs proudly said: 'Hey, this was my idea. I didn't know it would be like this. I didn't know it was this color' (Winge 2017). This drew attention to the children's understanding of scale (and being proudly surprised of being taken seriously), as playing with your fingers on a model obstacle course is an entirely different sensory experience than engaging with the body. 


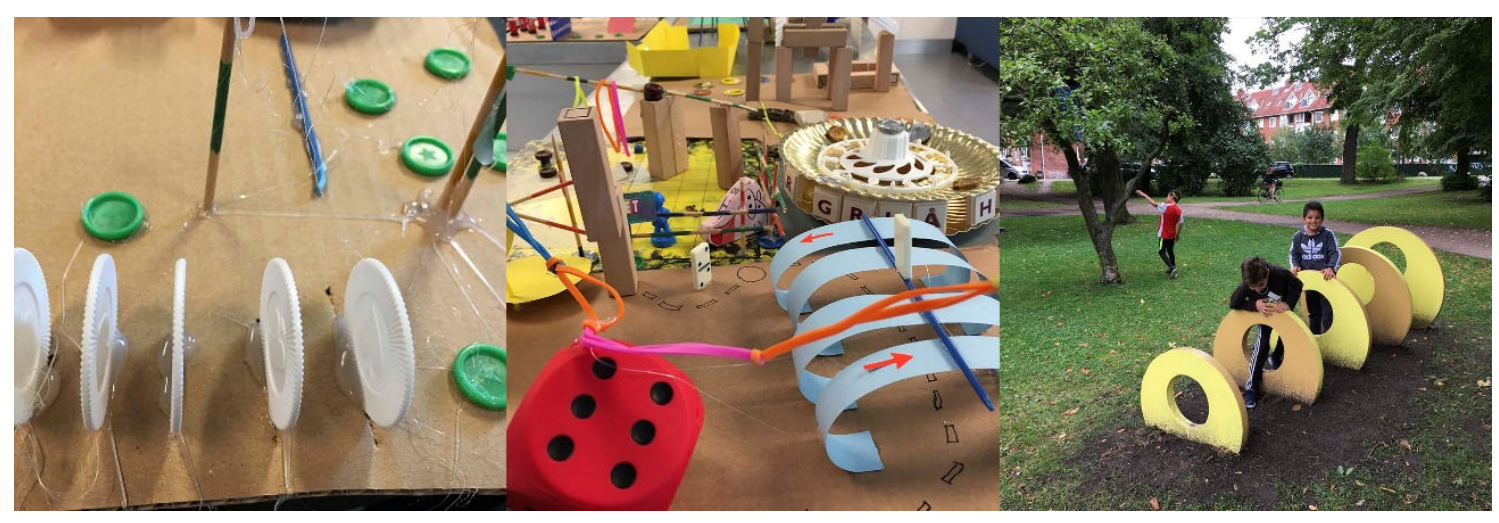

Figure 6. The relationship between the models and the final design. The disc-shaped goals were based on the model of a mini-obstacle course, utilizing the different holes employed both in play and in the models. Photos: Winge.

The everyday use of the disc-shaped goals shows how they inspire intuitive play, closely related to how play unfolded in the models. Through the transformation of scale, they invite the players to perform new actions: to get a ball through all of the holes in one single shot. The children tested this immediately after construction.

\section{Counter-use - designing through embodiment}

In workshop $\mathrm{D}$, we allowed for a high degree of adaptation in the design activity in order to explore the construction process. This entailed a merging of the production and design sphere with the public sphere (Ehn et al. 2014), with both the children and the researchers being active on the site. We employed a playful, intuitive approach to learning how to build. Every day, we invited interested children to participate, and we built the installations over three weeks. The designs that were not yet ready for construction were enacted and realized with the carpenters on site. The construction process was both an investigative experiment and a bodily engagement with the design. The process of making the installations provided a space for testing rules and boundaries, in terms of the 'right' use of tools and materials, as well as an 'embodied counter-use'. The embodied playing with the material as a sensory experience (Hackett \& Somerville 2017) was an example of material design/play, which led to interactions and dialogues about what design could be. While painting the rocking-boat, the children also applied paint to themselves, thereby 'transforming' themselves - a playful engagement with materials, the site and the emerging objects, modulating their surroundings and their own bodies in space.

The construction of the design entangled with play, e.g. the use of power tools, was both empowering and a power play (Figure 7). It made the children feel competent, and they played 'being builders' during the construction process.

One recurring pattern was the children's ability to step in and out of the construction process: one minute they were drilling, the next they were participants in an unrelated play activity elsewhere on the lawn. In this way, the making space was interwoven with playful on-site activities, which the children brought with them when they returned to the construction work. Some ideas evolved into messier, more 'slippery phenomena' (Law 2006). We had to train our minds to visit (Haraway 20I5) the slippery things, to be open to what might emerge from or matter in the design/play process, even if this 
meant taking seemingly unrelated detours. The children were designers at play - they were becoming the design; the design grew within the play.

How could we dive into these 'jelly' experiences of play as chaotic (Skovbjerg 2018), messy and productive moments? A child could become a game herself, intra-acting within the design/play process. The girl with arrows on her forehead was an example of 'jelly-ness': she was playing with her eyes. We could play the traditional role of adults, and ask her to focus on 'designing something buildable'. Or we could be curious (Haraway 2015): what if she was performing, in order to be a game herself? Was she exploring how her body connected with materiality, entering the design with play where we could not follow? Another girl played by poking her finger through a hole, teasing us and having fun. Her 'performance' resulted in the continuing investigation of holes, which led to the holes in the disc-shaped goals.

During the design/play testing, bodies entered into dialogue with the installations, and brought them to life. The site was enlivened through dialogue between body and design. Here, paidia provided a means of escape from underlying expectations of the workshop format, and thereby contributed to the design itself, adding new perspectives on the design/play activities and ensuing themes. The painting of the rocking-boat continued into the painting of the children. When they ran out of surfaces, they painted themselves and each other, appropriating their bodies as playable figures on the lawn. Play involving the embodiment and sensory experience of materials resulted in new solutions, or in unplanned, chaotic steps that were valuable for the design process. Looking at design/play as play with materials, and the 'jelly-ness' it creates (Figure 8), we can see that the children's engagement and entanglement with the materials was a step towards realizing 'something you can use with your body'. The quest was for materiality as a productive trait, to make play productive in its own right. In other words, the engagement arises from playing with the material.

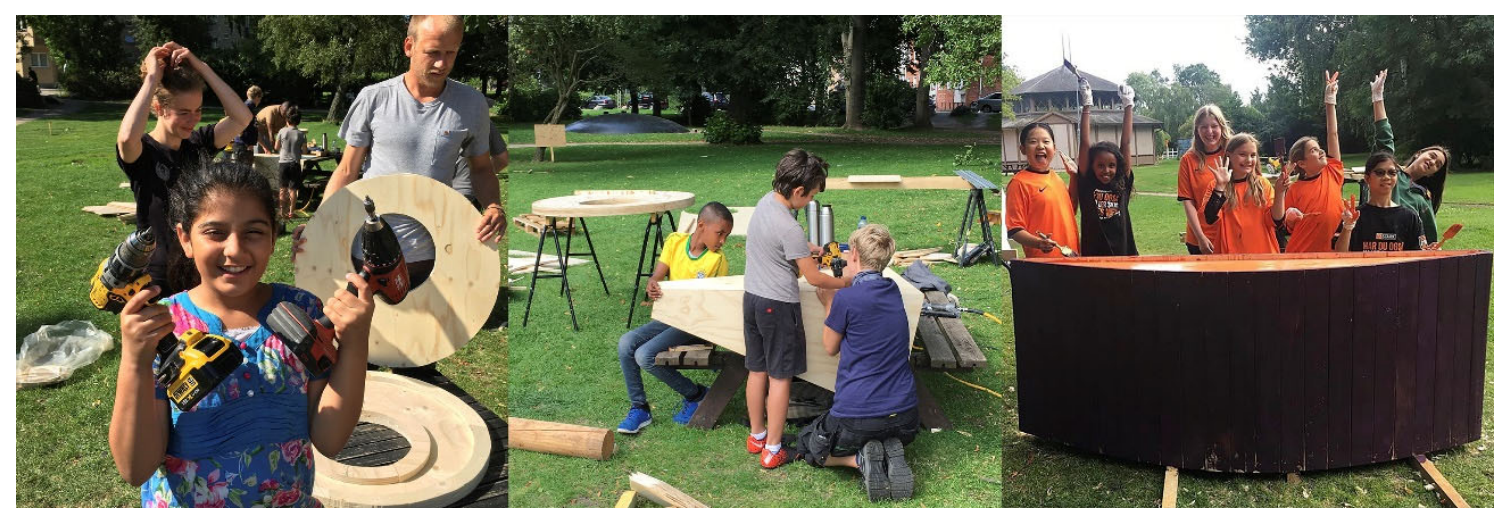

Figure 7. The enactment of capabilities for and decisions about construction. Power play with power tools: making your design together is empowering. Photos: Winge. Third photo: Lamm.

Figure 8 shows three examples of events that seemed 'messy' and 'jelly-like' in relation to the design outcome. The play itself did not offer any results, but suggested an 'empirical mess' or 'slippery phenomenon' (Law 2006). These events encouraged us to be curious (Haraway 2016) and see how the more-than-human world would play out, and therefore freed up the fieldwork. They cannot easily be described using the logic of 
design and construction, but they functioned as playful triggers in the design process and informed our thinking about design/play.

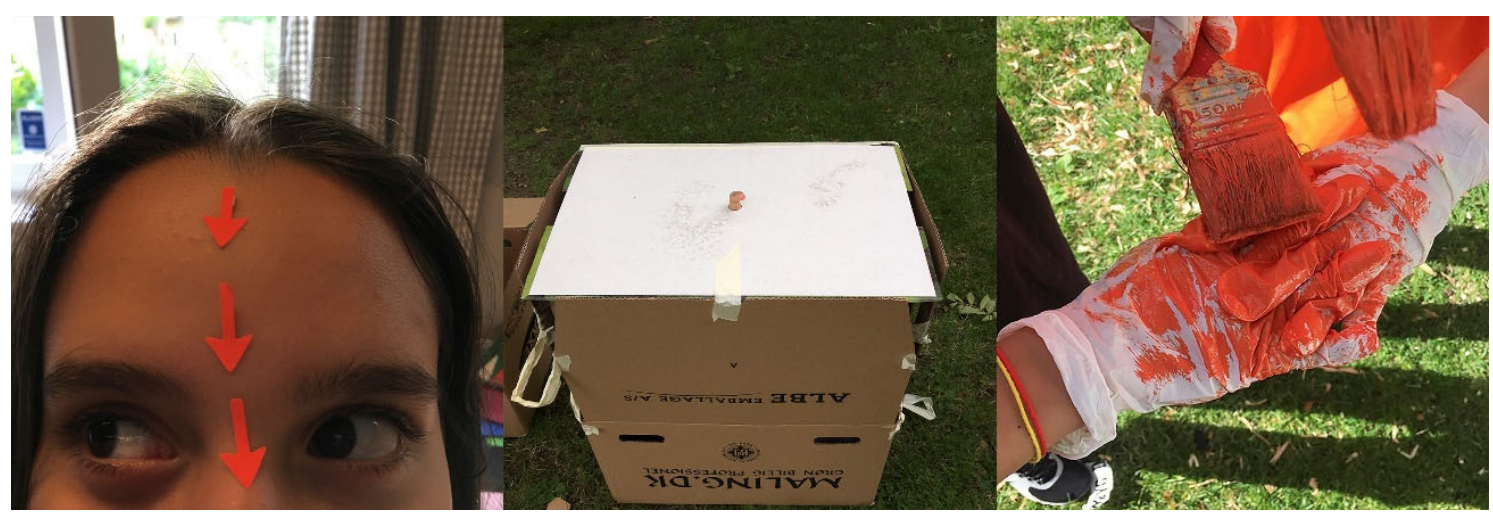

Figure 8. Embodiment with materials: Arrows on a forehead, a finger emerging from a hole. Children engaging with the materials by painting themselves. Photos: Winge. Third photo: Lamm.

5. Design negotiations in practice - from water to mirror

The creation of the mirror star-gate (Figure 9) is an example of 'polite visiting' (Haraway 20I5) through design dialogue. A design dialogue of transformative interactions took place between children and drawing. In workshop A, on I:I mock-ups, three girls designed a small bridge that also functioned as a seat. Beneath the bridge, they drew a stream, and imagined the sound of water - a poetic fishing opportunity, a place to sit with your BFF next to a watery reflection of a starry sky. The girls performed stories through their drawings.

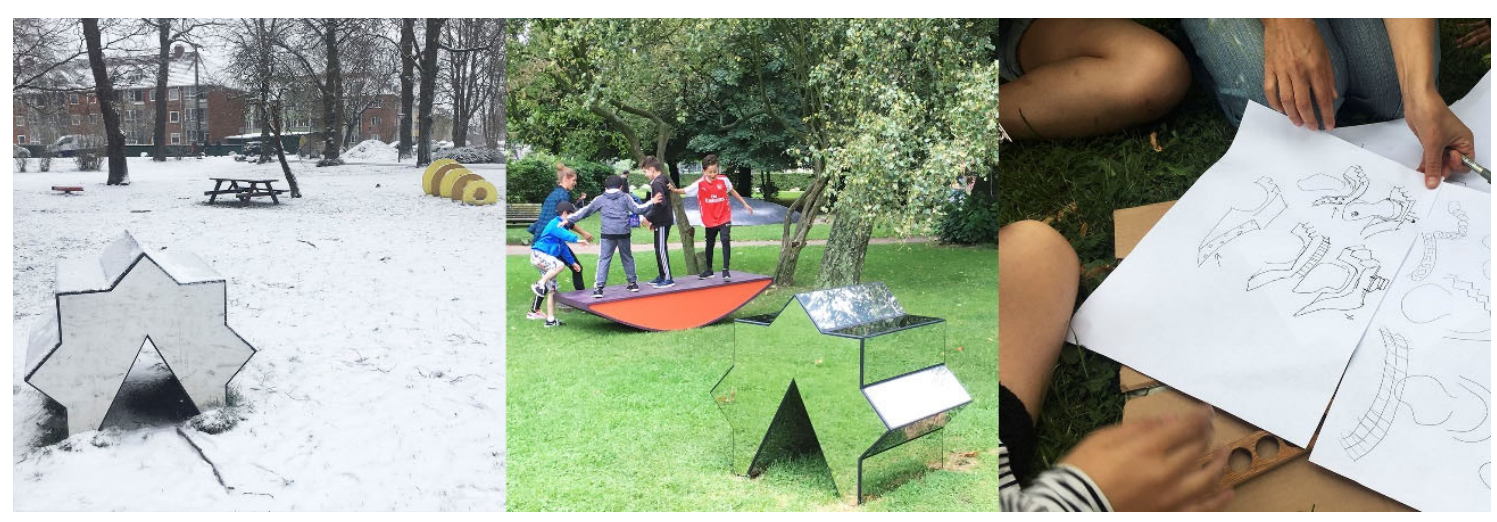

Figure 9. The mirror star-gate and the co-design process of telling and enacting. Negotiations through drawing stories between Winge and three girls. Photos: Winge. Third photo: Wagner.

With our explorative approach in mind, we tried to be open to being lost in play. However, while we were immersed in the design process, what was happening was not always obvious: "I was not playful at all. I was occupied with logistics, being practical and "adult". Even though we were connected by a playful, designerly dialogue, I insisted on something buildable' (Winge 2017).

Now, revisiting the negotiations, we can see that we opened up possibilities by asking questions: 'How can we build the water?' (Winge 2017). The dialogues and actions that 
produced the mirror star-gate exemplified the on-site breakout sessions aimed at realizing the children's specific design dreams and concerns. Such sessions were an important part of the process of refining the design solutions on the site. Specific objects, such as the mirror star-gate, were developed through dialogue between a researcher and a group of children who had concerns or specific ideas regarding the installation. These breakout sessions occurred away from the larger group, on nearby bench-and-table sets, which became an ad hoc outdoor design studio.

We took the time to draw and redraw, revisiting the design process multiple times, being curious and critical of each other's ideas. The dialogue between children and researchers was a process of transformation through drawing and play through words, in which the participants imagined themselves playing on the future site. We materialized the designs together through these intra-actions of drawing-imaginingconversations, and the ability to act emerged within this relationship (Kerr et. al. 2017). These playful dialogues of telling stories (Brandt et al. 20I2) unfolded the design: the water mirroring the starry sky became a mediator for mirroring the surroundings; the stairs to a bridge mediated the star, transforming the benches and creating the possibility of sitting on a star; the stars reflecting in the water slowly transformed into a mirror star; the sound of water became the sound of the wind in the trees; the bridge mediated a tunnel through which a ball could be kicked. In the end, these elements in the dialogue led to design choices that created an intervention that mirrored its surroundings, with more opportunities for play than we had anticipated: a seat, a platform to climb on and jump off, a tunnel to roll balls through. The most unexpected use was when a few children played on its surfaces and edges with finger-sized skateboards, returning the star to the world of miniature models, playing with scale and design/play.

\section{To catch an idea and throw it back}

In some events, design/play entailed the playful translation of ideas expressed through giggling 'jelly-ness'. Translating ideas into coherent designs, through dialogue and design/play inventions in groups, was a central part of co-designing. Two boys who giggled throughout the cardboard workshop ended up creating a tiny, moving model. Their giggling was a 'jelly-like' play/design approach to inventing a trigger that would surprise potential players. Everything was made in secret, and the design was conceived in whispers between the two boys.

When presenting their idea, they performed how to use it (Figure 10) by playing with their fingers, and giggled at how much fun it would be. Their model explored the idea of balance. Through play with a cardboard, finger-scaled model, they imagined game-play actions, and played out ludus and paidia through acts of balance. Playing it involved either balancing or falling off - rules immediately understood by the body. Here, playground safety regulations served as our 'shadow co-player'. We suggested a further refinements to their invention, in the form of the rocking-boat. 


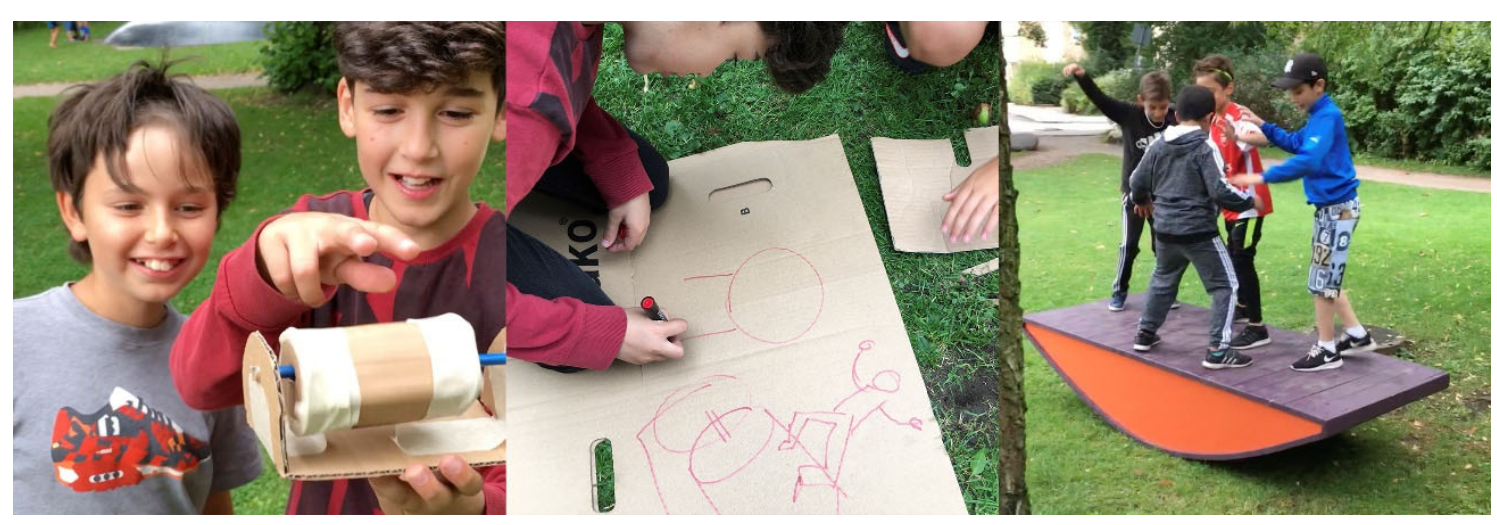

Figure 10. The boys play with their own balance-based invention. Players try to balance on the finished installation, the rocking-boat. Photos: Winge.

For the mirror star-gate, the dialogue took the form of a long negotiation conducted via drawing. For the rocking-boat, it was a quick 'design ping-pong dialogue', a reminiscent of good play of simply throwing and catching ideas.

\section{Discussion: Design/play}

The aim of this project was to explore whether new ways of designing playable spaces could emerge from a deconstruction of the rules for play and design. It revealed that the co-design process brought design/play into an intra-active sphere of collaborative, playful improvisation. We found that co-design, through telling, making and enacting on the site (Brandt et al. 2012), opened up practices in both the artistic and academic process, and through the entanglements of making and construction within the public sphere.

Design/play is one way (among many) of cultivating response-ability within co-design. According to Haraway, we cannot anticipate who and what we will visit. Diversity in play therefore opens up the participants in co-design to fun, dialogue and new potential. To discover what we are visiting, and how we are becoming response-able, we have to un-know why we are visiting. We acquire openness in the design process precisely by visiting the irrationalities of play. Un-knowing the design process is a curious practice. Our design/play events point to possible ways in which designers and researchers might act as polite visitors to facilitate co-design.

Just as rules were negotiated through play, the design and materials were negotiated through co-design enactments - the site, the participants, the artefacts and the design/play all intra-acted and drove the co-design and participants onward. Design/play nurtured creativity and connections in the participants, the design and the materials, thereby opening up intuitive decision-making and negotiations in the design process.

\section{Supporting open-endedness}

Did the method's messiness implement the 'jelly' experience of play, and thereby translate both clear design ideas and 'slippery phenomena' into playable design? Yes and no. We invited the slippery phenomena into the co-design process. As such, 'order' or identifying patterns - is a habitual act when designing. Translating ideas into 
constructed design necessitated a process of ordering and gathering. Order emerged through ludus and designerly negotiations, such as the processes that enacted the rocking-boat and the mirror star-gate. However, we also had to 'get lost' in paidia, to explore new possibilities for playable design, e.g. the way the tetherball totem was inspired by the small-scale models and robot costumes, and to acknowledge the creative disturbance of counter-play activities.

While using play as a driver could be understood as instrumental for effective design, this was not our intention. To see design/play as an intra-acting concept is to understand that play affects the process of design. Looking at the quality of play itself and meeting the children at their eye-level helps us to think differently about our understanding of design.

\section{Stories and materials as a stepping stone to design}

When investigating whether play could trigger new ways of thinking about and designing playable spaces, we see that design/play expands our design thinking. Actions such as art performances and materials like old board games can inspire the design of new games and open up collaborative thinking in the design/play process. This also relates to our actions, such as playing through 'gaming', 'designing' and power-play. In multiple ways, these identifications, via the process of making, frame the design/play actions. The way in which we approach these stories within the design process itself creates new design: 'It matters what stories we tell to tell other stories with' (Haraway 2016, p. 12). Stories, too, are players in the creation of poetic worlds through play. For example, the girls' playful dreaming of a world of water and stars was as real as the green grass and the drawings that negotiated the design. The imaginary world of playful stories becomes a driver of future design.

The joy of 'jelly-ness' contributes to an intuitive and responsive design practice - what we consider a curious practice. It supports an inductive way of opening doors, inviting the 'not-yet-known' to be part of design/play. By entering designerly dialogues in a spirit of openness, the participants commit to a mutual response-ability.

\section{Agency and capacity to act}

Despite our attempts to equalize the roles and power structures in the process, we recognize the role of other factors and circumstances, e.g. different decision-making capacities. Also, the installations were subject to certain inviolable safety rules. However, the openness to ambiguity within design/play enabled the children to destabilize some predefined roles and power structures, which is where play can have an empowering impact (Vaneycken in Hamers et al. 2017). The (adults') rules were deconstructed through play. Since play was a legitimate act of design, it was taken seriously, despite its unruliness, as part of the process of realizing design outcomes one was conditioned by the other.

So who was playing with whom? Facilitating play and design, turning messiness into something buildable, was about being response-able, combined with the capacity to make decisions. It was a structuring of design/play. This foregrounded the adults as controlling the framing of play, and the children as doing the playing. We, the adult 
researchers, liked to think that we were in control - or at least in control of being open to what might come.

Another perspective might be that the children were more response-able to openness while playing. In other words, it is possible that the children were playing with us, that they were the 'trickster-choreographers' of the 'subject-object-making dance' (Haraway 2015). 'If we design this, what will the grown-ups do?'

\section{Sum-up}

This paper has illustrated some of the dynamics within design/play. The research design intra-acted with co-design, context and collective 'reflection-in-action'. The design dialogues merged with collaborative play on site. The future public space and the discourse in the community entangled with new understandings of local playful activities through the transformation of the lawn into a playscape. We, the co-design researchers, paid - and played - the children a visit, and we visited the design process together. The introduction of objects such as old board games, art pieces and materiality functioned as participating tricksters that drove the ideas and the design thinking. We learned that response-ability is to the field what the mess and the jelly cake are to the description of the social experience of play.

The design/play process can be seen as a response-able approach to designing a playscape by exploring co-design as a dialogue between art, play and the design of public space. The playful negotiations and the final playscape can be understood through the phenomenon of design/play. We have unfolded the curious practice of design/play through what Haraway describes as a 'subject-and-object-making dance'. This enabled design to benefit from play - but by looking at design/play as intra-action, we also see that it enabled us to visit play as a phenomenon, and to understand design through a play mindset.

By participating in the design of a public space and engaging through design/play, the children came to recognize their own agency. We did not know what the right choices were, besides openness. We played, we prototyped, we got a little lost - an act of 'childhood roaming' in which the participants developed a kind of 'self-reliance, a sense of direction and adventure, imagination, a will to explore, to be able to get a little lost, and then figure out the way back' (Solnit 2006, p.7).

As we reflect on the experience of getting lost, being open to messy matters, we realize that the play structured something for us. However, we could not see it at the time, as we were proactively disturbed by all that ... play.

\section{Conclusion: Capturing the values of design/play}

We played, and we built a playscape that played with us. The playscape unfolds new possibilities for actions and encounters in the locality, and is response-able through its design. The process revealed that designing for public spaces can be truly playful. It can be open to and benefit from intuitive experiments and collective, productive messiness. Through a co-design process, we explored how the deconstruction of rules for play and design can trigger new ways of designing playable public spaces. The design/play approach and its inherent openness prompted the children to engage with the design of public space, free from implicit preconceptions about what design is, how it develops 
and what it looks like. In particular, the invitation to create new rules for free play in a public setting appealed to the children.

When we consider play and co-design, and how they relate and transform each other, it becomes clear that play opens up new ways of exploring, deconstructing and reassembling the design process. Design/play as an intra-acting phenomenon leads us to new imaginings and expands the boundaries of what a playable public space can be. Codesign as a curious practice is where participants (and design) become response-able to each other, and to implicit artefacts and design dialogues. The participatory elements, the determination to find meaning through play, are important qualities when designing public spaces with children.

However, a conscious and respectful treatment of the 'jelly-ness' of design/play is crucial. The aim of this paper has been to demonstrate how design/play can be methodologically productive in co-designing public spaces. Paradoxically, however, this playful productivity may be threatened if play is instrumentalized for a specific outcome. Hence, un-knowing the method - i.e. accepting the unruly, slippery parts of design/play - is important when we invite play into design.

When play becomes part of a curious practice and a conceptual tool for a response-able collaboration, our perspective shifts to the children's eye-level. We are connected with each other in the design process via an open field of possible actions. As designers, we learn to play by letting others visit us, by letting the design play with us, and by devoting ourselves to play and mess within the co-design of public playscapes.

\section{Acknowledgement}

We thank the APEN/'Move the Neighborhood' research team that collaborated on the overall research setup and provided insight and expertise that greatly assisted the project: Rene Kural, Kamilla Nørtoft and Sidse Carroll, Royal Danish Academy - Architecture, Design,

Conservation; Landscape Architecture and Planning, University of Copenhagen; and Jens Troelsen, Charlotte Skau Pawlowski and Tanja Schmidt, University of Southern Denmark. This research was supported by Områdefornyelsen Sydhavnen, the Danish Foundation for Culture and Sports Facilities, the Velux Foundations, and TrygFonden.

We thank the children and staff from Rubinen, the co-workers from the building company I.Maj, and the artist Molly Haslund (mollyhaslund.com).

We thank Eva Brandt, Professor at Lab for Social Design, the Design School Kolding; Kristina Lindström, Phd, Senior Lecturer at School of Arts and Communication at Malmö University; Pirjo Elovaara, PhD, Associate Professor, Head of Dept of Technology and Aesthetics, Blekinge Institute of Technology; and Melissa Van Drie, Marie-Curie Fellow at the Arts and Cultural Studies, University of Copenhagen - for reading and fruitful dialogues.

Thank you to the reviewers for their insightful comments.

\section{References}

Brandt, E., Binder, T. and Sanders, E. B. N. (20I2) Tools and techniques. Ways to engage telling, making and enacting. p. I45-180; Routledge International Handbook of Participatory Design, Simonsen, J. \& Robertson,T., Routledge, London.

Barad, K. (2003) Posthumanist Performativity: Toward An Understanding of How Matter Comes to Matter. March: Signs Journal of Women in Culture and Society 28(3):80I-83 I DOI: $10.1086 / 345321$ 
Barad, K. (2007/I996) Meeting the Universe Halfway. Duke University Press.

Caillois, R., (196I) Man, play, and games The Free Press of Glencoe, New York.

Ehn, P., Nilson, E. M. and Topgaard, R. (eds.) (2014) Making Futures - Marginal Notes on Innovation, Design, And Democracy. The MIT Press, Cambridge, Massachusetts, London, England.

Hackett, A. and Somerville, M. (2017) Posthuman literacies: Young children moving in time, place and more-than-human worlds. Journal of Early Childhood Literacy. 2017;17(3):374-39I. doi: I0.1 I77/|4687984|770403।

Haraway, D. J. (2016) Staying with the Trouble - Making Kin in the Chthulucene. Duke University Press, Durham and London.

Haraway, D. J. (20I2) A Curious Practice. Angelaki, 20:2, p.5-I4. DOI: 10.1080/0969725X.2015.1039817

Lykke, N. (2008) Kønsforskning - en guide til feministisk teori, metodologi og skrift. Forlaget Samfundslitteratur, Denmark.

Law, J. (2016) Making a Mess with Method, version of 19th January 2006, available at http://www. heterogeneities.net/publications/Law2006MakingaMesswithMethod.pdf, (downloaded on 24.09.2019).

Sanders E. B. N. and Stappers P. J. (2008) Co-creation and the new landscapes of design. CoDesign. 4(I):5-18.

Schön D. (1983) The Reflective Practitioner: How professionals think in action. London: Temple Smith.

Simonsen, J. \& Robertson, T. (eds.) (2013) Routledge International Handbook of Participatory Design, Routledge, ISBN 97804I57202I2

Skovbjerg, H. M. and Bekker, T. (eds.) (2006) The Value of Play - Inaugural Lectures by Professor Helle Marie Skovbjerg and Honorary Professor Tilde Bekker. (2018) Design School Kolding, Denmark.

Solnit, R. (2006) A Field Guide to Getting Lost. Canongate Books, Great Britain, Edinburgh.

Hamers, D., Mesquita, N. B., Vaneycken, A. and Schoffelen, J. (eds.) (2017) Trading Places Practices of Public Participation in Art and Design Research. Vaneycken, A. (20I7) Play. p. 67-73; Traders.

Vaneycken, A. (2020) Designing 'for' and 'with' ambiguity: actualising democratic processes in participatory design practices with children, doctoral thesis, University of Gothenburg. Faculty of Fine, Applied and Performing Arts, Sweden ISBN 978-9I-7833-858-0

\section{Other sources}

Lamm, B. (2017) Fieldnotes

Kerr, S., Adams, E. \& Pittard, B. (2017) http://makecommoningwork.fed.wiki/view/intra-action (Download 19.10.2020)

Skovbjerg, H. M. (2019) Professor at Lab for Play and Design, Design School Kolding, podcast at playful-learning.dk (Download 24.09.2019)

Winge, L. (2017) Fieldnotes

Young, A. and Haraway, D. J. (2019) On Staying with the Trouble / I3I. Interview, forthewild.world (Download 05.07.2020)

\section{Disclaimer}

All photos and research were carried out with the consent of both children, and children's parents. 